\title{
A New Piano-Stool Ruthenium(II) P-Cymene-Based Complex: Crystallographic, Hirshfeld Surface, DFT, and Luminescent Studies
}

\author{
Mohd. Muddassir*, Abdullah Alarifi and Mohd. Afzal \\ Catalytic Chemistry Research Chair, Department of Chemistry, College of Science, King Saud University, \\ Riyadh 11451, Saudi Arabia; arifi@ksu.edu.sa (A.A.); Afzalanalytical@gmail.com (M.A.) \\ * Correspondence: mmohammadarshad@ksu.edu.sa
}

Citation: Muddassir, M.; Alarifi, A.; Afzal, M. A New Piano-Stool Ruthenium(II) P-Cymene-Based Complex: Crystallographic, Hirshfeld Surface, DFT, and Luminescent Studies. Crystals 2021, 11, 13. https:/ / doi.org/10.3390/cryst11010013

Received: 8 December 2020 Accepted: 24 December 2020 Published: 26 December 2020

Publisher's Note: MDPI stays neutral with regard to jurisdictional claims in published maps and institutional affiliations.

Copyright: () 2020 by the authors. Licensee MDPI, Basel, Switzerland. This article is an open access article distributed under the terms and conditions of the Creative Commons Attribution (CC BY) license (https: / / creativecommons.org/ licenses/by/4.0/).

\begin{abstract}
A new complex $\left(\mathrm{Ru}\left(\eta^{6}-p\right.\right.$-cymene)(5-ASA)Cl 2$)$ (1) where 5-ASA is 5-aminosalicylic acid has been prepared by reacting the ruthenium arene precursors $\left(\left(\eta^{6} \text {-arene }\right) \mathrm{Ru}(\mu-\mathrm{Cl}) \mathrm{Cl}\right)_{2}$, with the 5-ASA ligands in a 1:1 ratio. Full characterization of complex 1 was accomplished by elemental analysis, IR, and TGA following the structure obtained from a single-crystal X-ray pattern. The structural analysis revealed that complex 1 shows a "piano-stool" geometry with Ru-C (2.160(5)2.208(5) $\mathrm{A}), \mathrm{Ru}-\mathrm{N}$ (2.159(4) Å) distances, which is similar to equivalents sister complex. Density functional theory (DFT) was used to calculate the significant molecular orbital energy levels, binding energies, bond angles, bond lengths, and spectral data (FTIR, NMR, and UV-VIS) of complex 1, consistent with the experimental results. The IR and UV-VIS spectra of complex 1 were computed using all of the methods and choose the most appropriate way to discuss. Hirshfeld surface analysis was also executed to understand the role of weak interactions such as $\mathrm{H} \cdots \mathrm{H}, \mathrm{C} \cdots \mathrm{H}, \mathrm{C}-\mathrm{H} \cdots \pi$, and $\mathrm{vdW}$ interactions, which play a significant role in the crystal environment's stability. Moreover, the luminescence results at room temperature show that complex 1 gives a more intense emission band positioned at $465 \mathrm{~nm}$ upon excitation at $330 \mathrm{~nm}$ makes it a suitable candidate for the building of photoluminescent material.
\end{abstract}

Keywords: ruthenium(II) p-cymene; Hirshfeld surface; DFT; H-bonding; luminescence

\section{Introduction}

Ruthenium is an essential class of $\pi$-donor metal ions, which exist in various oxidation states such as $\mathrm{Ru}(\mathrm{CO})_{4}{ }^{2-}$ and $\mathrm{RuO}_{4}$ [1]. Among them, ruthenium(II) and ruthenium(III) complexes are the most stable and expected to display antitumor activity that is different from those of platinum-based drugs [2], hence their credible importance in therapeutic application [3]. Besides, the low reduction potential, high electron transferability, and increased interaction with heteroatoms make ruthenium superior to other metal ions [4]. $\mathrm{Ru}(\mathrm{II})$ complexes have been not only widely used as antibacterial [5], antifungal [6], and antitumor agents [7], but also involves in various steps of organic synthesis and catalytic activity, e.g., $\alpha$-alkylation [8], hydrogenation, isomerization, reductive elimination $[9,10]$, and C-H activation catalysis, etc. [11]. Nevertheless, the nature of the ligands coordinated to ruthenium ion plays a crucial role in stabilizing various oxidation states via tuning the metallic center's redox properties [12]. Consequently, lack of stability is a significant concern for ruthenium(II)/(III)-based complexes responsible for its undesired local reactivity. Hence, the complex stability could be improved by inserting a ligand, further stabilizing the molecule. Thereby, improved stability and better reactivity could be achieved.

Hence, the design of new ligands containing different functional groups with electron donor capability should be very interesting for ruthenium metal complexes. Moreover, 5-Aminosalicylic acid (5-ASA) and its derivatives are used as chelating ligands in homoor heterometallic system of transition metals and lanthanides [13-16]. Metal complex of 
5-ASA exhibited a wide range of biological activities and, most notably, in therapeutics to combat many inflammatory diseases such as Crohn's disease and ulcerative colitis [17]. In addition, the structural and spectral characterizations of new half-sandwich ruthenium(II) complexes containing these kind of ligands are of great importance.

In this context, considerably, effort has been paid on the development of organoruthenium complexes having ruthenium-carbon bonds for many years in various fields [18]. There are several metal salts of ruthenium, out of which ruthenium(II) ( $p$-cymene) has a special place as it possesses substituted benzene, which in turn stabilizes the molecules through stacking interactions of coordinated aromatic molecules, and thus acts as good model system to study the influence of substituents. Additionally, $\mathrm{Ru}(\mathrm{II}) p$-cymene complexes have brought a large group of molecules, which show different mechanism of action [19-21]. Hence, the examination of such types of complexes directed their optimistic role as anticancer agent, antibacterial drugs [22-24], alkene polymerization, ring-opening metathesis [25-27], hydrogen transfer catalyst precursors [28,29], olefin oxidation [30,31], and redox-active photosensitizers for solar cells [32-34]. The majority of the application of ruthenium half-sandwich compounds are in the field of biological assay, and other areas are unexplored to understand the mechanism of such complexes fully. In the past few decades, density functional theory (DFT) techniques have been routinely employed to get more insight about the structural and electronic properties of the complexes in lieu of experimental results due to its trustworthy outcomes with thoughtful computational cost in contrast to higher level $a b$ initio methods [35-37].

Recently, Malenov and coworker has analyzed the most frequent stacking interactions between aromatic rings of p-cymene ligands of transition metal complexes, as well as $\mathrm{C}-\mathrm{H} / \pi$ interactions flanked by methyl substituents by performing DFT calculations, which further establishes the presence of substituents on coordinated aromatic rings that can lead to substantial alterations in the geometries. Moreover, the stacking interactions significantly reinforce the overall networks by generating additional contacts with aromatic rings and thus, provides crucial information for ruthenium-based half-sandwich complexes [38]. Similarly, Chi's group has explored the anion sensing $\left(\mathrm{F}^{-}, \mathrm{Cl}^{-}, \mathrm{NO}_{3}{ }^{-}, \mathrm{PF}_{6}{ }^{-}, \mathrm{CH}_{3} \mathrm{COO}^{-}\right.$, and $\mathrm{C}_{6} \mathrm{H}_{5} \mathrm{COO}^{-}$) ability of two different dinuclear arene ruthenium complexes using fluorescence titration experiment, which showed a large fluorescence enhancement upon binding to these multicarboxylate anions owing to the hindrance of photoinduced electron transfer process from the ruthenium-arene to the amidic donor in dinuclear arene based ruthenium complexes [39].

Herein, we have synthesized a new ruthenium(II) (p-cymene) complex 1 containing 5-ASA as a ligand and structurally characterized using various analytical and spectroscopic techniques and further confirmed by single-crystal X-ray diffraction pattern. DFT calculations at B3LYP/ZORA/D3BJ level are performed on the complex 1 to elucidate the electronic as well as geometrical features and bonding nature of the complex, which recognized that $\mathrm{CH} \cdots \pi$ and $\mathrm{H}$-bonding interactions were involved in the stabilization of the complex. A Hirshfeld surface analysis is also implemented to generate two-dimensional fingerprint plots, which validate the type of weak interactions occurring in the supramolecular network of complex 1. Furthermore, the emission behavior of complex 1 was studied at room temperature that displayed an intense band at $465 \mathrm{~nm}$ that mainly originates from the ruthenium(II) (p-cymene) moiety, which could make it a suitable material for the building of photoluminescent material. It is important to note that the emission properties of these kinds of organometallic half-sandwich complexes are sensitive to the substituents on the ligands as reported by others.

\section{Experimental}

\subsection{Starting Materials}

Analytical grade reagents and solvents were procured from commercial sources and used without further purification. 


\subsection{Synthesis}

$\left(\mathrm{Ru}\left(\eta^{6}\right.\right.$-p-cymene $\left.)(5-\mathrm{ASA}) \mathrm{Cl}_{2}\right)(\mathbf{1})$

To a methanolic solution $(10 \mathrm{~mL})$ of $\left(\mathrm{Ru}\left(\eta^{6}-\mathrm{p} \text {-cymene }\right) \mathrm{Cl}_{2}\right)_{2}(61.2 \mathrm{mg} 0.1 \mathrm{mmol}), 5$ ASA ( $30.6 \mathrm{mg} 0.2 \mathrm{mmol}$ ) dissolved in $10 \mathrm{~mL}$ methanol was added, and the mixture was stirred at room temperature for $2 \mathrm{~h}$. Thereafter, the solution was kept at room temperature until a red precipitate was formed, which was washed with hexane and then dried. Red color crystals were obtained after they were recrystallized from dichloromethane${ }^{n}$ hexane solvent mixture. Yield: $56.6 \%$. Anal. Calc. for $\mathrm{C}_{17} \mathrm{H}_{21} \mathrm{Cl}_{2} \mathrm{NO}_{3} \mathrm{Ru}(\%) \mathrm{C}, 44.45$; $\mathrm{H}, 4.61$; and N, 3.05, Found: C, 46.18; H, 4.54; and N, 2.99. $\wedge_{\mathrm{M}}\left(1 \times 10^{-3} \mathrm{M}\right.$, acetonitrile): $17.0 \Omega^{-1} \mathrm{~cm}^{2} \mathrm{~mol}^{-1}$ ( nonelectrolyte).

The details of X-ray crystal refinement, protocols related to DFT and Hirshfeld surface analyses have been provided in supporting information (See the Supplementary Materials).

\section{Results and Discussion}

\subsection{Synthetic Methodology}

Complex 1 has been achieved from the reaction of ruthenium(II) $p$-cymene chloride with 5-ASA ligand in methanol under ambient conditions. The complex is stable towards air and moisture and soluble in most of the organic solvents. The structure elucidation of $\mathbf{1}$ is established by single-crystal X-ray, ESI-MS, microanalysis, TGA, and IR and NMR $\left({ }^{1} \mathrm{H}\right.$ and $\left.{ }^{13} \mathrm{C}\right)$ spectroscopies. Molar conductance value of complex in acetonitrile solution $\left(1 \times 10^{-3} \mathrm{M}\right)$ at $25^{\circ} \mathrm{C}$ suggests its nonelectrolyte nature $\left(17.0 \Omega^{-1} \mathrm{~cm}^{2} \mathrm{~mol}^{-1}\right)$.

\subsection{X-ray Structure Investigation}

Single crystals suitable for X-ray analysis were attained from the slow evaporation of dichloromethane- ${ }^{\mathrm{n}}$ hexane solvent mixture. The structure of the complex $\mathbf{1}$ is illustrated in Figure 1A. The crystallographic data are listed in Table 1, while the bond distances and bond angles are provided in Table 2 . The structure of complex $\mathbf{1}$ is a ruthenium complex with p-cymene and 5-ASA. Each Ru atom coordinates two $\mathrm{Cl}^{-}$anions, aromatic ring of $p$-cymene, and 5-ASA through nitrogen atom forming tetrahedral coordination geometry $(\mathrm{CN}=4)$. The single crystal $\mathrm{X}$-ray analysis reveals that the complex $\mathbf{1}$ crystallizes as a monoclinic crystal system with space group $P 2_{1} / n$. Only one molecule is present in the asymmetric unit and had a characteristic three-legs piano-stool geometry. A $\eta^{6}-\pi$-bonded $p$-cymene arene ring is forming the seat and other three donor atoms (one nitrogen atom of 5-ASA moiety and two chlorine atoms) turns as legs of the stool. The bond lengths between $\mathrm{Ru}-\mathrm{N}$ and $\mathrm{Ru}-\mathrm{Cl}$ are $2.159(4)$ and $2.4005-2.4304 \AA$, respectively, as reported previously for $\mathrm{Ru}$ (II) $p$-cymene complexes [40]. However, Ru-C ( $p$-cymene) bond lengths are in the range of $2.160-2.208 \AA$, consistent with those similar types of mononuclear complexes reported earlier.

Further simplification of a crystal structure to its underlying net in so-called standard representation of the valence-bonded complexes in which all ruthenium atoms and the centers of mass of ligands are nodes of the underlying net [41]. The underlying net can be considered the simplest net that stores the information on the system's overall topology of the structural units chosen according to a chemical vision of the crystal structure, where "simplest" means that the net cannot be more simplified with the secondary simplification procedure. Studying the underlying net, one can abstract from details of complex groups' molecular structure and search for long-range resemblances of complexes of different compositions and architectures.

Such representation shows that no net and structure is consisting of molecular complex groups (Figure 1A, right). It forces us to perform further analysis taking into account $\mathrm{H}$ bonding. In this approach, ruthenium polyhedra is considered as net nodes connected with $\mathrm{H}$-bonds. H-bonded standard representation results into 5-c uninodal underlying net (Figure 1B). The net topology is tts with point symbol $\left\{3^{3} \cdot 4^{3} \cdot 5^{4}\right\}$. This net is two dimensional;

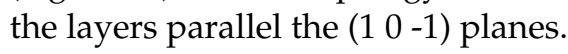


(A)

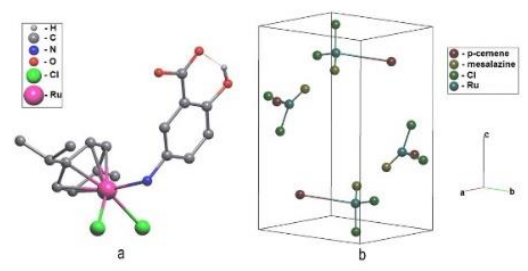

(C)

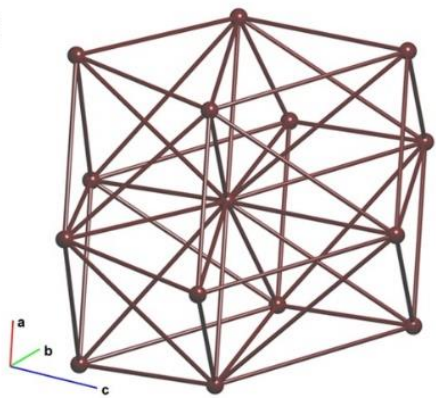

(B)

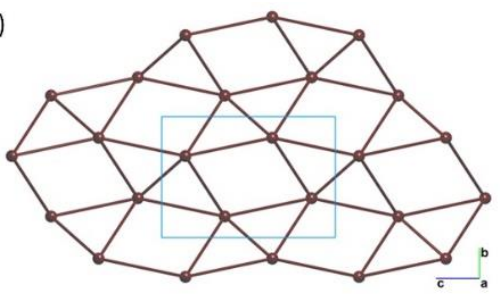

(D)

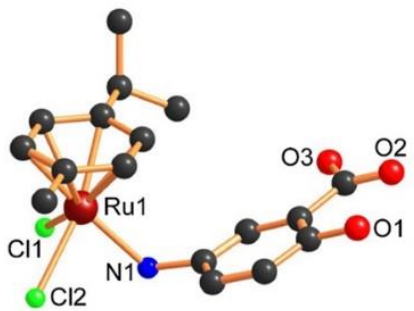

Figure 1. (A) Molecular structure of the complex 1 monomer (left) and standard representation of the group with 1,4M5-1 topology (right). Hydrogen atoms that do not participate in hydrogen bonding are omitted for clarity. (B) Underlying net in standard representation of the H-bonded molecular MOFs corresponds to tts topological type. The unit cell of the structure is shown with a blue line. (C) Underlying net in standard representation of the Coulomb or vdW-bonded molecular structures corresponds to bcu-x topological type. (D) Density functional theory (DFT)-optimized structures of complex 1. Thermal ellipsoids were shown at 50\% probability. Hydrogen atoms have been omitted for clarity.

Table 1. Crystal structural data and refinement parameters for complex $\mathbf{1 .}$

\begin{tabular}{cc}
\hline CCDC No. & $\mathbf{2 0 3 8 4 5 2}$ \\
\hline Formula & $\mathrm{C}_{17} \mathrm{H}_{21} \mathrm{Cl}_{2} \mathrm{NO}_{3} \mathrm{Ru}$ \\
Formula weight & 459.32 \\
Temperature/K & 150 \\
Crystal system & Monoclinic \\
Space group & $\mathrm{P} 2_{1} / \mathrm{n}$ \\
$a / \AA$ & $8.6496(15)$ \\
$b / \AA$ & $12.026(3)$ \\
$c / \AA$ & $17.285(3)$ \\
$\alpha /{ }^{\circ}$ & 90.00 \\
$\beta /{ }^{\circ}$ & $91.976(6)$ \\
$\gamma /{ }^{\circ}$ & 90.00 \\
Volume $^{\circ} \AA^{3}$ & $1796.9(6)$ \\
$\mathrm{Z}$ & 4 \\
$\rho_{\text {calc }} / \mathrm{mg}^{-3} m^{-1}$ & 1.698 \\
$\mu / \mathrm{mm}^{-1}$ & 9.930 \\
$F(000)$ & 928.0 \\
& $-7 \leq \mathrm{h} \leq 10$ \\
Index ranges & $-14 \leq \mathrm{k} \leq 15$ \\
& $-21 \leq 1 \leq 19$
\end{tabular}

$a: R_{1}=\left(\Sigma|| F_{\mathrm{o}}|-| F_{\mathrm{c}}||\right) / \Sigma\left|F_{\mathrm{o}}\right| . b: w R_{2}=\left[\Sigma\left[w\left(F_{\mathrm{o}}{ }^{2}-F_{\mathrm{c}}{ }^{2}\right)^{2}\right] / \Sigma\left[w\left(F_{\mathrm{o}}{ }^{2}\right)^{2}\right]\right]^{1 / 2}$, where $w=1 /\left[\sigma^{2}\left(F_{\mathrm{o}}{ }^{2}\right)\right.$ $\left.+(\alpha P)^{2}+b P\right]$.

Standard representation of the Coulomb or vdW-bonded molecular structures is 3D framework. Resulted 14-c uninodal net has bcu-x topological type with point symbol $\left\{3^{36} \cdot 4^{48} \cdot 5^{7}\right\}$ as shown in Figure $1 \mathrm{C}$.

We opted the DFT method as an alternative to validate the complex 1 molecular structure. Geometry optimization of complex $\mathbf{1}$ were performed without symmetry restrictions, and the resulting structures are presented in Figure 1D. Validation of the structural parameters like bond distances $(\AA)$ and bond angles (deg) obtained from X-ray analysis 
and theoretical calculation (DFT) has been made for complex $\mathbf{1}$ (Table 2), which indicates a significant resemblance to each other.

Table 2. Selected bond distances ( $)$ and angles (degrees) for $\mathbf{1}$.

\begin{tabular}{cccc}
\hline & & \multicolumn{2}{c}{ Complex 1 } \\
\cline { 3 - 4 } & & X-ray & DFT \\
\hline & $\mathrm{Ru}(1)-\mathrm{Cl}(1)$ & $2.4005(16)$ & 2.453 \\
\hline $\mathrm{Ru}(1)-\mathrm{Cl}(2)$ & $2.4304(14)$ & 2.458 \\
\hline $\mathrm{Ru}(1)-\mathrm{N}(17)$ & $2.159(4)$ & 2.174 \\
\hline $\mathrm{Ru}(1)-\mathrm{C}(10)$ & $2.195(5)$ & 2.193 \\
\hline & $\mathrm{Ru}(1)-\mathrm{C}(9)$ & $2.208(5)$ & 2.204 \\
\hline & $\mathrm{Ru}(1)-\mathrm{C}(11)$ & $2.171(5)$ & 2.183 \\
\hline $\mathrm{Ru}(1)-\mathrm{C}(12)$ & $2.185(5)$ & 2.212 \\
\hline $\mathrm{Ru}(1)-\mathrm{C}(13)$ & $2.160(5)$ & 2.228 \\
\hline $\mathrm{Ru}(1)-\mathrm{C}(14)$ & & $2.193(5)$ & 2.204 \\
\hline $\mathrm{Rl}(1)$ & $\mathrm{Ru}(1)$ & $86.89(5)$ & 88.54 \\
\hline $\mathrm{N}(1)$ & $\mathrm{Ru}(1)$ & $81.78(13)$ & 80.96 \\
\hline $\mathrm{N}(1)$ & $\mathrm{Cl}(2)$ & $81.41(13)$ & 82.15 \\
\hline
\end{tabular}

\subsection{NMR Spectroscopy}

Complex 1 shows all the characteristic signals arising from coordinated arene rings and 5-ASA (Figure S1). The resonances due to the 5-ASA ligand are shifted with respect to those of free 5-ASA ascribed to its coordination. The signal of $-\mathrm{NH}_{2}$ in free 5-ASA appeared at $2.5 \mathrm{ppm}$ as a singlet has been moved to $3.15 \mathrm{ppm}$ confirming its coordination to Ru(II) center. Resonance of $\eta^{6}$-p-cymene protons appeared as two doublets at 5.8-5.75 ppm. Resonances of methyl groups in $\eta^{6}$-p-cymene moiety of complex 1 appeared at $1.18-1.17 \mathrm{ppm}$.

In ${ }^{13} \mathrm{C}$ NMR spectrum, signals at around 206 and $171 \mathrm{ppm}$ corresponds to (-COOH) and (-CO), respectively, in addition to aromatic carbon signals, which appeared at 100.1-124.8 ppm (Figure S2). The $\eta^{6}$-p-cymene carbon resonances found at 86.3-85.5 ppm corresponds to $(\mathrm{C}-\mathrm{CHMe} 2), 30.6-29.9$ ppm belongs to $\left(\mathrm{CH}\left(\mathrm{CH}_{3}\right)_{2}\right)$, whereas $21.4 \mathrm{ppm}$ corresponds to $\left(\mathrm{CH}\left(\mathrm{CH}_{3}\right)_{2}\right)$, and $17.8 \mathrm{ppm}$ corresponds to $\left(\mathrm{C}-\mathrm{CH}_{3}\right)$ in complex 1 . These chemical shift values are consistent with those reported for similar $\left(\operatorname{Ru}\left(\eta^{6}-\mathrm{p}\right.\right.$-cymene $\left.)\right)$ complexes [18].

\subsection{IR Spectroscopy}

The IR spectra of complex 1 was recorded in the region of $4000-400 \mathrm{~cm}^{-1}$ (Figure 2A,B) and their comparison have been made from calculated frequencies in order to validate the structure. The calculated frequencies in terms of relative intensities and vibrational assignments are in good agreement with the experimental frequencies, as presented in Table 3. The slight deviation observed in the theoretical value arises from the fact that calculations have been carried out in gas phase, while the experimental data have been achieved on an isolated complex in the solid state, which happens to be a typical error for this particular basis set.

The band at $1666 \mathrm{~cm}^{-1}$ has been assigned to the symmetric stretching of carboxyl group $-\mathrm{C}=\mathrm{O}$ with $-\mathrm{OH}$ symmetric bend and is computed at $1741 \mathrm{~cm}^{-1}$ but the experimental vibration remained undisturbed, indicating that the carboxylate group of 5-ASA is not involved in the coordination to $\mathrm{Ru}(\mathrm{II})$ metal ion [16,42]. The other two bands observed at 1623 (DFT: $1684 \mathrm{~cm}^{-1}$ ) and $1593 \mathrm{~cm}^{-1}$ (DFT: $1641 \mathrm{~cm}^{-1}$ ) are attributed to ring deformation with $\mathrm{C}=\mathrm{C}$ stretch and $\mathrm{C}-\mathrm{H}$ bending localized on the 5-ASA ring. The band at $1531 \mathrm{~cm}^{-1}$ is assigned to $-\mathrm{NH}_{2}$ scissoring which is expected by DFT at 
$1602 \mathrm{~cm}^{-1}$. The stretching vibrations because of $\mathrm{C}-\mathrm{H}$ (aliphatic and aromatic) group are observed in the range of $2800-3150 \mathrm{~cm}^{-1}$ and are theoretically found in the range of 3020-3231 $\mathrm{cm}^{-1}$. The N-H symmetrical and asymmetrical stretching vibrations were observed at 3219 (DFT: $3408 \mathrm{~cm}^{-1}$ ) and $3285 \mathrm{~cm}^{-1}$ (DFT: $3488 \mathrm{~cm}^{-1}$ ), respectively. The broadening observed at $3350-3500 \mathrm{~cm}^{-1}$ has been ascribed to the -OH stretching vibrations [43]. The other calculated IR assignments are given in Table 3, which is consistent with the corresponding experimental values.

The infrared spectrum calculation of these vibrations will help the study these types of ruthenium(II) (p-cymene) and even clarify some experiments and theories of arguing. These results can enhance the characterization and help to discover the contribution of ligand components to these kinds of ruthenium(II) (p-cymene) complexes.

(A)

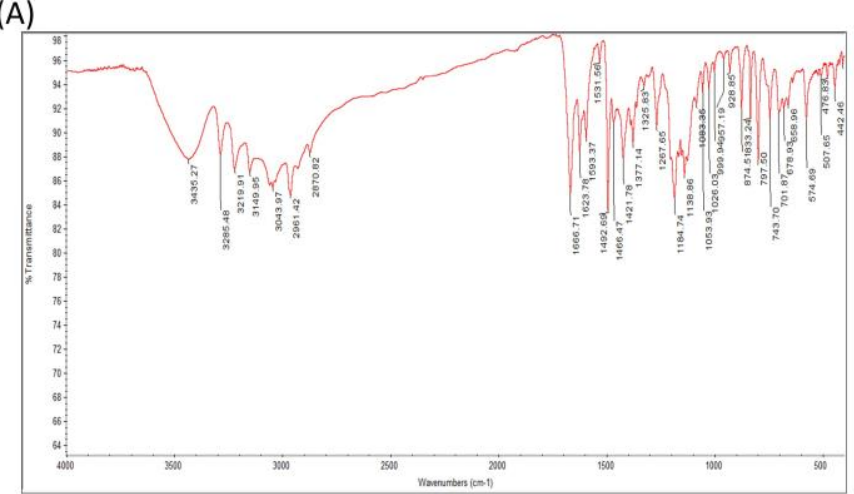

(C)

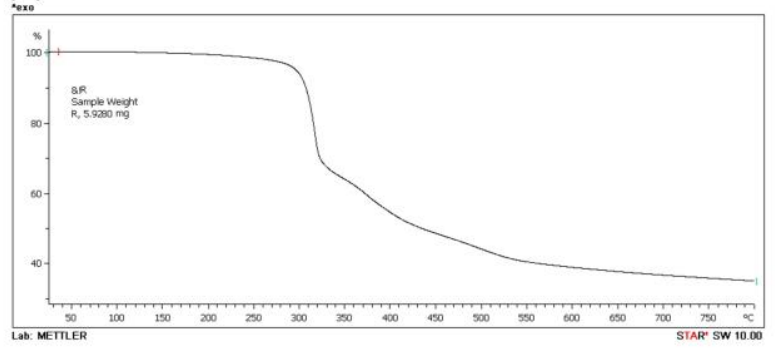

(B)

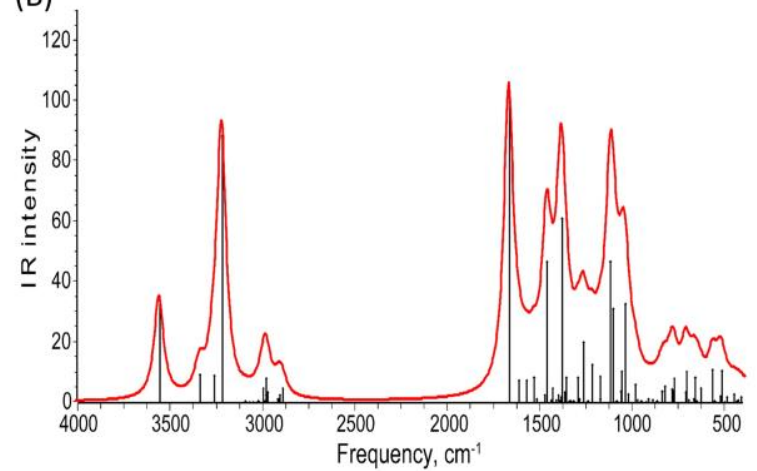

(D)

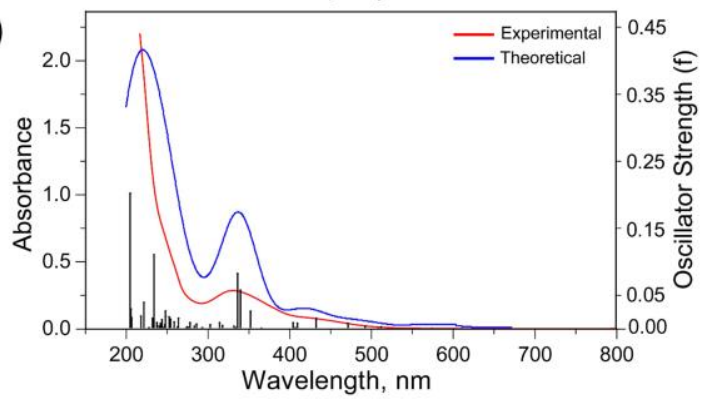

Figure 2. Complex 1 showing (A) IR spectrum, (B) DFT-simulated vibrational spectrum (C) TGA, and (D) experimental and TDDFT (Time-Dependent Density-Functional Theory) calculated UV-VIS spectra (calculated singlet electronic transitions are shown as black vertical bars with height equal to their oscillator strength).

\subsection{Thermogravimetric Analysis}

The thermogram for complex $\mathbf{1}$ (Figure 2C) was recorded in the temperature range of $25-800{ }^{\circ} \mathrm{C}$, which shows three steps weight loss pattern. It is observed that the complex 1 loses $32.15 \%$ (calculated $33.26 \%$ ) in the temperature range from 50 to $310{ }^{\circ} \mathrm{C}$ designates the removal of 5-ASA. Beyond this temperature, complex 1 starts decomposition. Finally, the TGA curve displayed a plateau around $650{ }^{\circ} \mathrm{C}$, consistent with other previously reported half-sandwich ruthenium (II) (p-cymene) complexes [30].

\subsection{Absorption Study}

Since we also wanted to investigate the stability of complex 1 , after determining the complex's three-dimensional structure in crystalline state, the next step was to define the energy minima conformation thereof. Frontier molecular orbitals (FMO) have an important role for giving an insight into the chemical reactivity's and some of the physical properties. The spectral properties of transition metal complexes are strongly related to the energy of these orbitals. We have performed the TDDFT calculation on complex $\mathbf{1}$, 
at the B3LYP/ZORA/D3BJ level to distinguish their singlet excited states and electronic properties (Figure 2D).

Table 3. Experimental and density functional theory (DFT) calculated IR spectra for complex 1, (wavenumber in $\mathrm{cm}^{-1}$ ).

\begin{tabular}{|c|c|c|}
\hline \multicolumn{3}{|c|}{ Complex 1} \\
\hline Experimental & DFT & Inference \\
\hline 574 & 590 & Out-of-plane ring deformation \\
\hline 701 & 740 & O-H wagging \\
\hline 743 & 817 & In-plane ring deformation \\
\hline 874 & $878-925$ & Ar-CH wagging \\
\hline 999 & 997 & Ar-CH twisting \\
\hline 1026 & 1027 & $-\mathrm{CH}_{3}$ rocking \\
\hline 1053 & 1066 & $-\mathrm{CH}_{3}$ rocking \\
\hline 1184 & 1131 & Ar- $\mathrm{CH}$ rocking \\
\hline 1267 & 1264 & $\mathrm{CH}$ twisting \\
\hline 1421 & 1427 & $\mathrm{CH}$ scissoring \\
\hline 1492 & 1497 & Ar-C-C asymmetric stretching \\
\hline 1531 & 1602 & $-\mathrm{NH}_{2}$ scissoring \\
\hline 1593 & 1641 & $\mathrm{C}=\mathrm{C}$ stretch and $\mathrm{C}-\mathrm{H}$ bending \\
\hline 1623 & 1684 & $\mathrm{C}=\mathrm{C}$ stretch and $\mathrm{C}-\mathrm{H}$ bending \\
\hline 1666 & 1741 & $-\mathrm{C}=\mathrm{O}$ symmetric stretching \\
\hline 2870 & $3020-3040$ & $\mathrm{CH}_{3}$ symmetric stretching \\
\hline 2961 & $3104-3160$ & $\mathrm{CH}$ Asymmetric stretching \\
\hline 3043 & $3186-3231$ & Ar-CH symmetric stretching \\
\hline 3219 & 3363 & Ar-O-H (phenolic) symmetric stretching \\
\hline 3285 & 3265 & $-\mathrm{NH}_{2}$ symmetric stretching \\
\hline 3435 & 3560 & $\mathrm{O}-\mathrm{H}(\mathrm{COOH})$ symmetric stretching \\
\hline
\end{tabular}

It is evident from Figure 2D that the absorbance tail at 400-500 $\mathrm{nm}$ region is influenced by metal-centered and metal-to-ligand charge transfer $\left({ }^{1} \mathrm{MLCT}\right)$ transitions and major contribution is assigned to HOMO- $1 \rightarrow \mathrm{LUMO}+3$ excitation. A few ${ }^{1} \mathrm{MLCT}$ transitions are partially dissociative, since they have considerable contributions from $\mathrm{Ru}-\mathrm{N}(\mathrm{L}) \sigma^{*}$ antibonding orbitals. Nearly pure ${ }^{1} \mathrm{MLCT}(\mathrm{Ru} \rightarrow \mathrm{L})$ states are found in the higher energy (ca. 300-480 nm), assigned to HOMO-3 $\rightarrow$ LUMO excitation. However, a more pronounced peak at $220 \mathrm{~nm}$ is attributed to the mixed ${ }^{1} \mathrm{MLCT} /{ }^{1} \mathrm{LC}$ (ligand centered) transition, which is in good agreement with the experimental UV-VIS spectrum. The orbital arrangements of computed singlet transitions are shown in Figure 3. Though the simulated spectrum of the title compound in the gas phase has given a reasonable agreement on the band maximum positions with the experiment result, the calculation including solvent effect was also carried out with the expectation of a better match-up between the simulated and the experimental value. 

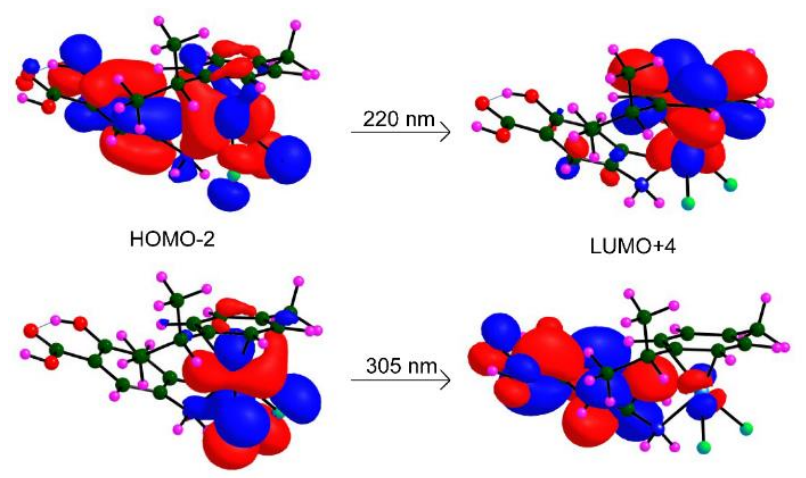

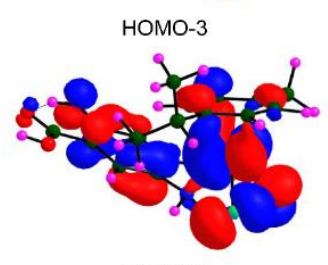

HOMO-1

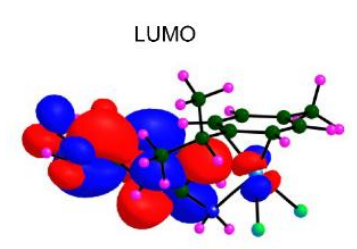

$\mathrm{LUMO}+3$

Figure 3. Frontier molecular orbitals (FMO) involved in electronic transitions observed in TDDFT calculated UV-VIS spectrum of complex 1.

\subsection{Hirshfeld Surface Analyses}

The Hirshfeld surface is a useful tool for describing the surface characteristics of molecules. To explore the intermolecular interactions as the function of distance $\left(\mathrm{d}_{\mathrm{e}}, \mathrm{d}_{\mathrm{i}}\right.$, $\mathrm{d}_{\text {norm, }}$, and $2 \mathrm{~d}$ fingerprint plots) in the crystal system, Hirshfeld surface (HS) analysis was carried out [44]. The HS of complex $\mathbf{1}$ is mapped over $\mathrm{d}_{\text {norm }}$ (normalized contact distance), and shape-index and curvedness were generated on an asymmetric unit of the complex 1 . The red, white, and blue color conventions in the $d_{\text {norm }}$ images were associated with the distance shorter, equal, and longer than the van der Waals radii, respectively. As shown in Figure $4, d_{\text {norm }}$ was mapped in the color range of -0.2 to $0.8 \AA$, deep red spots observed in $\mathrm{d}_{\text {norm }}$ were formed due to shorter contacts indicative of $\mathrm{O} \cdots \mathrm{H}$ interactions, while fainted red spots were due to $\mathrm{C} \cdots \mathrm{H}$ interactions. The white zones denote interactions about the van der Waals separation like $\mathrm{H} \cdots \mathrm{H}$ contacts and the blue areas are devoid of close contacts. Beside this, other properties of HS analysis like shape-index and curvedness provides evidence about the weak interactions in the molecular packing. In the shape-index $(-1.0$ to $1.0 \AA)$ analysis of complex $\mathbf{1}$, both the red areas attributing to C-H $\cdots \pi$ interactions as well as "bow-tie patterns," which indicated the existence of $\pi \cdots \pi$ stacking interactions. The curvedness points to surface curves electronic density around the molecular contacts. In the $d_{\text {norm }}$ surface of complex 1 , blue and white surfaces are more prevailing than red surface, which indicated that the hydrophobic interaction due to the aromatic ring is dominated. The dark red and blue color spots are distribution in the shape index surface that suggested the presence of $\mathrm{C}-\mathrm{H} \cdots \pi$ interaction in the complex 1 .
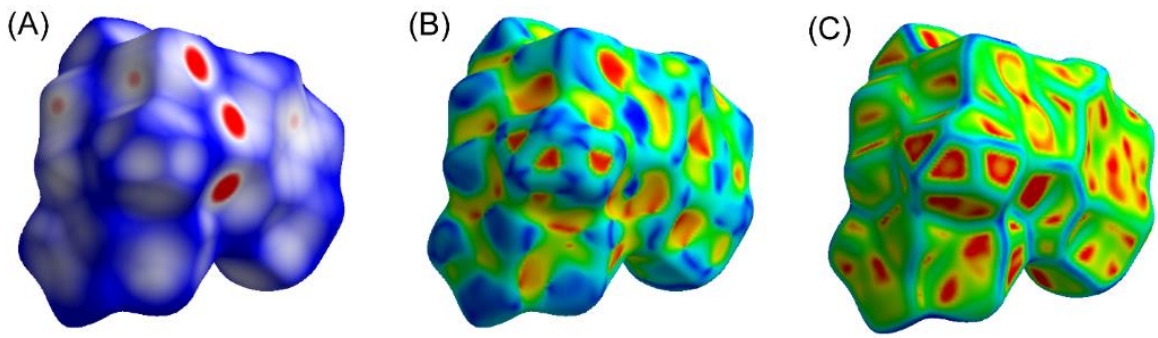

Figure 4. Hirshfeld surfaces mapped with $d_{\text {norm }}(\mathbf{A})$, shape index (B), and curvedness (C) for complex 1. 
Further, 2-D fingerprint plots are used for quantitative analysis that can be split into particular atom pair close contacts. The shape index is highly sensitive to very subtle changes in the surface shape; the information conveyed by the shape index are consistent with 2D fingerprint plots. The curvedness is the measurement of "how much shape" there is in a crystal. The flat areas of the surface correspond to low values of curvedness, whereas sharp curvature areas correspond to high values of curvedness and usually tend to divide the surface into patches, indicating interactions between neighboring molecules. The 2D fingerprint plots can be deconstructed to highlight particular atom pair contacts. This deconstruction enables the separation of contributions from different interaction types that overlap in the full fingerprint.

The overall fingerprint plot analysis for complex $\mathbf{1}$ is given in Figure 5. It exposed that the most significant contribution in the framework comes from $\mathrm{H} \cdots \mathrm{H}$ interaction $(45.30 \%)$ of the total HS. However, remaining proportions of $\mathrm{Cl} \cdots \mathrm{H}, \mathrm{O} \cdots \mathrm{H}, \mathrm{C} \cdots \mathrm{H}$, and C...C interactions include $20.10 \%, 18.90 \%, 10.20 \%$, and $4.2 \%$, respectively, of the total HS for each molecule. $\mathrm{H} \cdots \mathrm{H}$ interactions make up the majority of the Hirshfeld surface, which is consistent with the high proportion of hydrogen atoms in the complex 1 . The central spike in the fingerprint plot was due to the $\pi \cdots \pi$ interactions formed between the flanked benzene ring.

The Hirshfeld surface analysis confirms the importance of $\mathrm{H}$-atom contacts in establishing the packing. The large number of $\mathrm{H} \cdots \mathrm{H}, \mathrm{Cl} \cdots \mathrm{H}, \mathrm{O} \cdots \mathrm{H}, \mathrm{C} \cdots \mathrm{H}$, and $\mathrm{C} \cdots \mathrm{C}$ interactions suggest that van der Waals interactions and hydrogen bonding play the major roles in the crystal packing.
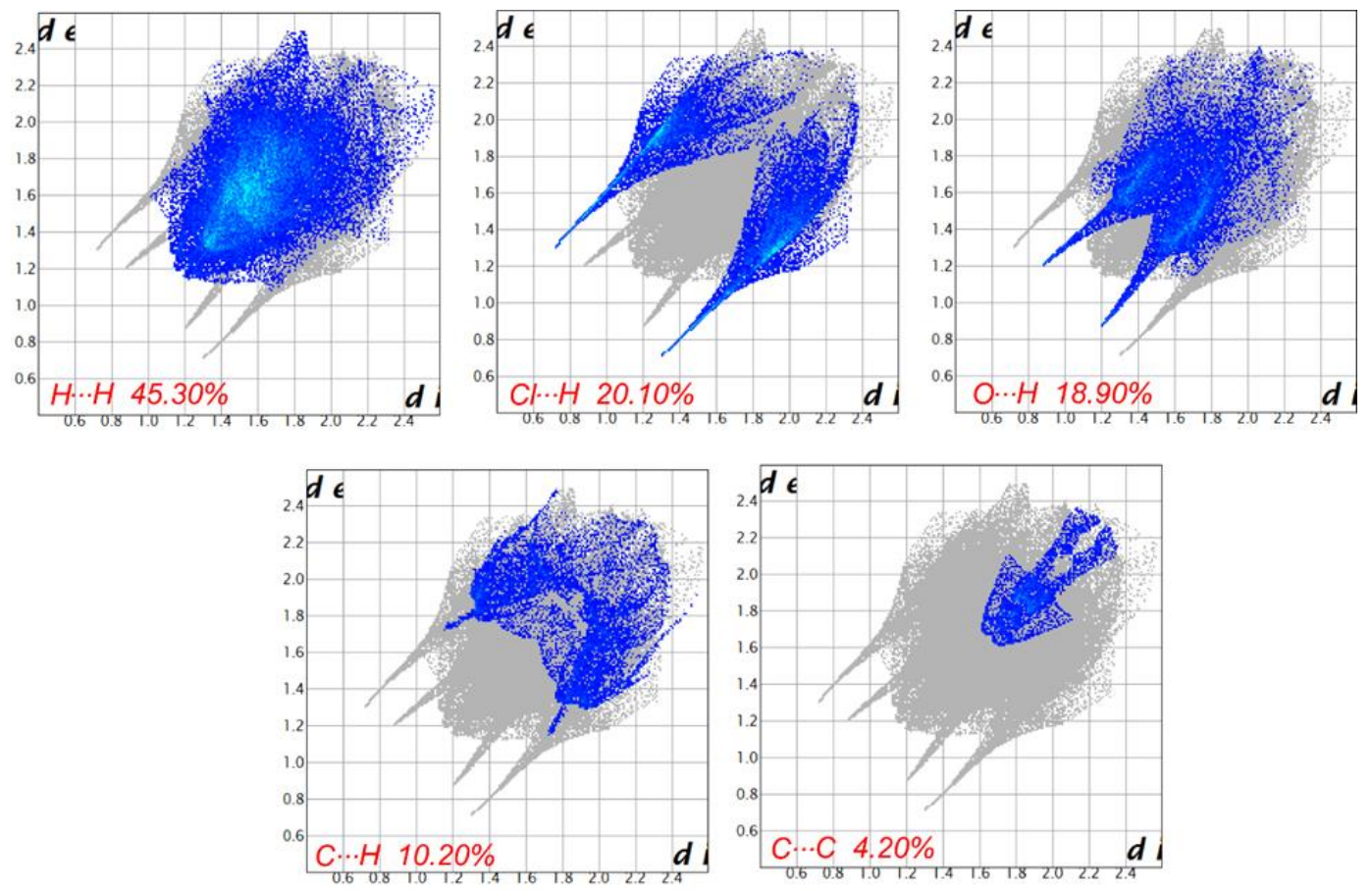

Figure 5. The 2D fingerprint plots for complex 1.

\subsection{Photoluminescence Property}

The emission profile of ruthenium(II) (p-cymene)-based complexes is of much interest due to their unique emissive nature, originating from the $\pi$-arene group, which has ability to tune the photoluminescence properties [45]. The emission studies of ruthenium(II) (p-cymene) complex were monitored at room temperature in acetonitrile, showing an unstructured intense band at $465 \mathrm{~nm}$ upon excitation at $330 \mathrm{~nm}$ as shown in Figure 6. It seems that the emission largely originates from the ruthenium(II) ( $p$-cymene) moiety. Thus, 
it can be concluded that the emission bands of complex $\mathbf{1}$ is attributed to a metal-ligand charge transfer (MLCT) state. It is important to note that the emission properties of these kinds of organometallic half-sandwich complexes are sensitive to the substituents on the ligands as reported by others [32].

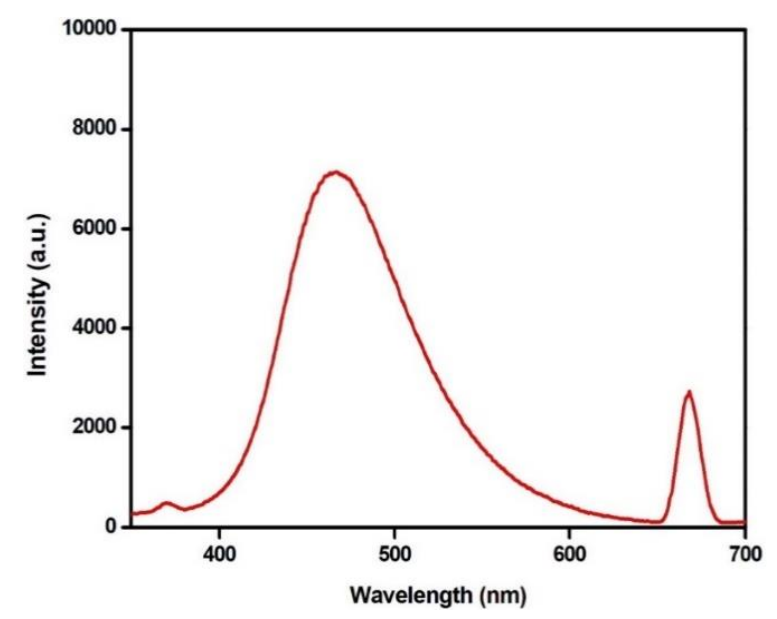

Figure 6. Emission spectra for complex $1\left(\lambda_{\mathrm{ex}}=330 \mathrm{~nm}\right)$.

Being a strong luminescence property, complex $\mathbf{1}$ could have suitable applications as fluorescent material.

\section{Conclusions}

A new mononuclear $\left(\mathrm{Ru}\left(\eta^{6}-p\right.\right.$-cymene)(5-ASA) $\left.\mathrm{Cl}_{2}\right)$ complex $\mathbf{1}$ has been isolated and fully identified by NMR, IR, TGA MS, elemental analysis, UV-VIS spectroscopy. The single crystal X-ray analysis revealed that complex $\mathbf{1}$ crystallizes in a monoclinic space group $P 2_{1} / \mathrm{n}$ and exhibited a usual three-legged piano-stool geometry. The $\mathrm{Ru}(\mathrm{II})$ metal ion is coordinated by a nitrogen atom of 5-ASA, two chloride ligands and the $p$-cymene ligand (with an $\eta^{6}$ coordination mode). The coordination environment around the $\mathrm{Ru}$ (II) metal center can be recognized as a distorted octahedron. The presence of two chloride ligands is responsible for the stabilization of the crystal framework. DFT calculations were also performed, revealing the geometric and bond features of the novel complex. Considering all intermolecular contacts during the simplification procedure, we obtain a description of the excellent molecular packing. The strong luminescence property of the complex $\mathbf{1}$ makes it an ideal candidate as photoluminescent material considering the improved property as reported by others. It should be noted that the reported complex and similar types of such complexes further warrant their use for the development of photoluminescent probe in biological system and sensing application.

Supplementary Materials: The following are available online at https:/ /www.mdpi.com/2073-4 352/11/1/13/s1, Table S1: The details of X-ray crystal refinement, protocols related to density functional theory (DFT) and Hirshfeld surface analyses; Figure S1: ${ }^{1} \mathrm{H}$ NMR spectrum of complex 1; Figure S2: ${ }^{13} \mathrm{C}$ NMR spectrum of complex 1.

Author Contributions: Conceptualization, M.M., and A.A.; methodology, M.M.; validation, M.M., A.A. and M.A.; formal analysis, M.M.; investigation, A.A.; resources, M.M.; data curation, M.M.; writing —original draft preparation, M.A.; writing—review and editing, M.M.; visualization, A.A.; supervision, M.M.; project administration, M.M.; funding acquisition, M.M. All authors have read and agreed to the published version of the manuscript.

Acknowledgments: The authors extend their sincere appreciation to the Deputyship for Research \& Innovation, "Ministry of Education" in Saudi Arabia, for funding this research work through the project number IFKSURG-1440-076.

Conflicts of Interest: The author declares no conflict of interest. 


\section{References}

1. Sarı, Y.; Gürses, C.; Celepci, D.B.; Keleştemur, Ü.; Aktaş, A.; Yüksel, Ş.; Ateş, B.; Gök, Y. 4-Vinylbenzyl and 2-morpholinoethyl substituted ruthenium(II) complexes: Design, synthesis, and biological evaluation. J. Mol. Struct. 2020, 1202, 127355. [CrossRef]

2. Reedijk, B.J. Metal-Ligand Exchange Kinetics in Platinum and Ruthenium Complexes. Platin. Met. Rev. 2008, 52, 2-11. [CrossRef]

3. Notaro, A.; Gasser, G. Monomeric and dimeric coordinatively saturated and substitutionally inert Ru( II) polypyridyl complexes as anticancer drug candidates. Chem. Soc. Rev. 2017, 46, 7317-7337. [CrossRef] [PubMed]

4. Lozano-Vila, A.M.; Monsaert, S.; Bajek, A.; Verpoort, F. Ruthenium-Based Olefin Metathesis Catalysts Derived from Alkynes. Chem. Rev. 2010, 110, 4865-4909. [CrossRef]

5. Liao, X.; Jiang, G.; Wang, J.; Duan, X.; Liao, Z.; Lin, X.; Shen, J.; Xiong, Y.; Jiang, G. Two ruthenium polypyridyl complexes functionalized with thiophen: Synthesis and antibacterial activity against Staphylococcus aureus. N. J. Chem. 2020, 44, 17215-17221. [CrossRef]

6. Golbaghi, G.; Groleau, M.; López de los Santos, Y.; Doucet, N.; Déziel, E.; Castonguay, A. Cationic Ru II Cyclopentadienyl Complexes with Antifungal Activity against Several Candida Species. ChemBioChem 2020, 21, 3112-3119. [CrossRef]

7. Chen, J.; Wang, J.; Deng, Y.; Li, B.; Li, C.; Lin, Y.; Yang, D.; Zhang, H.; Chen, L.; Wang, T. Novel cyclometalated Ru(II) complexes containing isoquinoline ligands: Synthesis, characterization, cellular uptake and in vitro cytotoxicity. Eur. J. Med. Chem. 2020, 203, 112562. [CrossRef]

8. Murugan, K.; Vijayapritha, S.; Kavitha, V.; Viswanathamurthi, P. Versatile formation of Ru(II) hydrazone complexes: Structure, theoretical studies and catalytic activity in $\alpha$-alkylation. Polyhedron 2020, 190, 114737. [CrossRef]

9. Trnka, T.M.; Grubbs, R.H. The Development of L 2 X 2 RuCHR Olefin Metathesis Catalysts: An Organometallic Success Story. Acc. Chem. Res. 2001, 34, 18-29. [CrossRef]

10. Van der Drift, R.C.; Bouwman, E.; Drent, E. Homogeneously catalysed isomerisation of allylic alcohols to carbonyl compounds. J. Organomet. Chem. 2002, 650, 1-24. [CrossRef]

11. Wang, H.-X.; Wu, K.; Che, C.-M. Metal-Quinoid Carbene Chemistry: From Bonding to C-H Activation Catalysis. Synlett 2020. [CrossRef]

12. Jabłońska-Wawrzycka, A.; Rogala, P.; Michałkiewicz, S.; Hodorowicz, M.; Barszcz, B. Ruthenium complexes in different oxidation states: Synthesis, crystal structure, spectra and redox properties. Dalt. Trans. 2013, 42, 6092-6101. [CrossRef] [PubMed]

13. Shahabadi, N.; Moradi Fili, S.; Shahlaei, M. Synthesis, characterization and comparative DNA interaction studies of new copper(II) and nickel(II) complexes containing mesalamine drug using molecular modeling and multispectroscopic methods. J. Coord. Chem. 2015, 68, 3667-3684. [CrossRef]

14. Soliman, M.H.; Mohamed, G.G. Cr(III), Mn(II), Fe(III), Co(II), Ni(II), Cu(II) and Zn(II) new complexes of 5-aminosalicylic acid: Spectroscopic, thermal characterization and biological activity studies. Spectrochim. Acta Part A Mol. Biomol. Spectrosc. 2013, 107, 8-15. [CrossRef] [PubMed]

15. Zhang, X.; Lei, X.; Dai, Z. Synthesis and Characterization of Light Lanthanide Complexes with 5-Aminosalicylic Acid. Synth. React. Inorg. Met. Chem. 2004, 34, 1123-1134. [CrossRef]

16. Arjmand, F.; Muddassir, M. Design and synthesis of heterobimetallic topoisomerase I and II inhibitor complexes: In vitro DNA binding, interaction with 5'-GMP and 5'-TMP and cleavage studies. J. Photochem. Photobiol. B Biol. 2010, 101, 37-46. [CrossRef] [PubMed]

17. Nigović, B.; Šimunić, B. Determination of 5-aminosalicylic acid in pharmaceutical formulation by differential pulse voltammetry. J. Pharm. Biomed. Anal. 2003, 31, 169-174. [CrossRef]

18. Purkait, K.; Mukherjee, A. Cytotoxicity and reactivity of a redox active 1,4-quinone-pyrazole compound and its Ru(II)-p-cymene complex. Inorganica Chim. Acta 2020, 502, 119361. [CrossRef]

19. Štarha, P.; Trávníček, Z. Non-platinum complexes containing releasable biologically active ligands. Coord. Chem. Rev. 2019, 395, 130-145. [CrossRef]

20. Kenny, R.G.; Marmion, C.J. Toward Multi-Targeted Platinum and Ruthenium Drugs-A New Paradigm in Cancer Drug Treatment Regimens? Chem. Rev. 2019, 119, 1058-1137. [CrossRef]

21. Thota, S.; Rodrigues, D.A.; Crans, D.C.; Barreiro, E.J. Ru(II) Compounds: Next-Generation Anticancer Metallotherapeutics? J. Med. Chem. 2018, 61, 5805-5821. [CrossRef] [PubMed]

22. Bergamo, A.; Sava, G. Linking the future of anticancer metal-complexes to the therapy of tumour metastases. Chem. Soc. Rev. 2015, 44, 8818-8835. [CrossRef] [PubMed]

23. Clarke, M.J. Ruthenium metallopharmaceuticals. Coord. Chem. Rev. 2002, 232, 69-93. [CrossRef]

24. Motswainyana, W.M.; Ajibade, P.A. Anticancer Activities of Mononuclear Ruthenium(II) Coordination Complexes. Adv. Chem. 2015, 2015, 1-21. [CrossRef]

25. Ogo, S.; Uehara, K.; Abura, T.; Watanabe, Y.; Fukuzumi, S. Aqueous Polymerization of Styrene Promoted by Water-Soluble Robust Ruthenium Hydride Complexes. Organometallics 2004, 23, 3047-3052. [CrossRef]

26. Demonceau, A.; Dragutan, I.; Dragutan, V.; Le Gendre, P. Olefin Metathesis as Key Step in the Synthesis of Bioactive Compounds: Challenges in the Total Synthesis of Iriomoteolides. Curr. Org. Synth. 2012, 9, 779-790. [CrossRef]

27. Stumpf, A.W.; Saive, E.; Demonceau, A.; Noels, A.F. Ruthenium-based catalysts for the ring opening metathesis polymerisation of low-strain cyclic olefins and of functionalised derivatives of norbornene and cyclooctene. J. Chem. Soc. Chem. Commun. 1995, 1127-1128. [CrossRef] 
28. Canivet, J.; Karmazin-Brelot, L.; Süss-Fink, G. Cationic arene ruthenium complexes containing chelating 1,10-phenanthroline ligands. J. Organomet. Chem. 2005, 690, 3202-3211. [CrossRef]

29. Šterk, D.; Stephan, M.S.; Mohar, B. New chiral N-(N,N-dialkylamino)sulfamoyl-1,2-diamine ligands for highly enantioselective transfer hydrogenation of ketones. Tetrahedron Asymmetry 2002, 13, 2605-2608. [CrossRef]

30. Gichumbi, J.M.; Friedrich, H.B.; Omondi, B. Synthesis and characterization of piano-stool ruthenium complexes with $N, N^{\prime}-$ pyridine imine bidentate ligands and their application in styrene oxidation. J. Organomet. Chem. 2016, 808, 87-96. [CrossRef]

31. Marchetti, F.; Pettinari, C.; Pettinari, R.; Cerquetella, A.; Di Nicola, C.; Macchioni, A.; Zuccaccia, D.; Monari, M.; Piccinelli, F. Synthesis and Intramolecular and Interionic Structural Characterization of Half-Sandwich (Arene)Ruthenium(II) Derivatives of Bis(Pyrazolyl)Alkanes. Inorg. Chem. 2008, 47, 11593-11603. [CrossRef] [PubMed]

32. Rüther, T.; Woodward, C.P.; Jones, T.W.; Coghlan, C.J.; Hebting, Y.; Cordiner, R.L.; Dawson, R.E.; Robinson, D.E.J.E.; Wilson, G.J. Synthesis, characterisation, and properties of p-cymene Ruthenium(II) tetracarboxylate bipyridine complexes [( $\eta 6-\mathrm{p}-$ cymene)Ru(Rn,Rn'-tcbpy)Cl][Cl]. J. Organomet. Chem. 2016, 823, 136-146. [CrossRef]

33. Nazeeruddin, M.K.; Zakeeruddin, S.M.; Lagref, J.-J.; Liska, P.; Comte, P.; Barolo, C.; Viscardi, G.; Schenk, K.; Graetzel, M. Stepwise assembly of amphiphilic ruthenium sensitizers and their applications in dye-sensitized solar cell. Coord. Chem. Rev. 2004, 248, 1317-1328. [CrossRef]

34. Barolo, C.; Yum, J.-H.; Artuso, E.; Barbero, N.; Di Censo, D.; Lobello, M.G.; Fantacci, S.; De Angelis, F.; Grätzel, M.; Nazeeruddin, M.K.; et al. A Simple Synthetic Route to Obtain Pure Trans -Ruthenium(II) Complexes for Dye-Sensitized Solar Cell Applications. ChemSusChem 2013, 6, 2170-2180. [CrossRef]

35. Martinho, M.; Xue, G.; Fiedler, A.T.; Que, L., Jr.; Bominaar, E.L.; Münck, E. Mössbauer and DFT Study of the Ferromagnetically Coupled Diiron(IV) Precursor to a Complex with an $\mathrm{Fe}^{\mathrm{IV}}{ }_{2} \mathrm{O}_{2}$ Diamond Core. J. Am. Chem. Soc. 2009, 131, 5823-5830. [CrossRef]

36. Kal, S.; Filatov, A.S.; Dinolfo, P.H. Structural, Electrochemical, and Spectroscopic Investigation of Acetate Bridged Dinuclear Tetrakis-Schiff Base Macrocycles of Mn and Zn. Inorg. Chem. 2013, 52, 13963-13973. [CrossRef]

37. Maxwell, C.I.; Mosey, N.J.; Stan Brown, R. DFT Computational Study of the Methanolytic Cleavage of DNA and RNA Phosphodiester Models Promoted by the Dinuclear Zn (II) Complex of 1,3-Bis(1,5,9-triazacyclododec-1-yl)propane. J. Am. Chem. Soc. 2013, 135, 17209-17222. [CrossRef]

38. Malenov, D.P.; Zarić, S.D. Stacking interactions between ruthenium p -cymene complexes: Combined crystallographic and density functional study. CrystEngComm 2019, 21, 7204-7210. [CrossRef]

39. Mishra, A.; Lee, S.; Kim, H.; Cook, T.R.; Stang, P.J.; Chi, K.-W. Selective Detection of Multicarboxylate Anions based on "Turn on" Electron Transfer by Self-Assembled Molecular Rectangles. Chem. An. Asian J. 2012, 7, 2592-2599. [CrossRef]

40. Vinoth, G.; Indira, S.; Bharathi, M.; Durgadevi, A.; Abinaya, R.; Alves, L.G.; Martins, A.M.; Bharathi, K.S. Synthesis of Imines via Reactions of Benzyl Alcohol with Amines Using Half-Sandwich ( $\eta^{6}-p$-cymene) Ruthenium(II) Complexes Stabilised by 2-aminofluorene Derivatives. Appl. Organomet. Chem. 2019, 33, e5200. [CrossRef]

41. Alexandrov, E.V.; Blatov, V.A.; Kochetkov, A.V.; Proserpio, D.M. Underlying nets in three-periodic coordination polymers: Topology, taxonomy and prediction from a computer-aided analysis of the Cambridge Structural Database. CrystEngComm 2011, 13, 3947-3958. [CrossRef]

42. Liu, J.; Lin, Y.; Liu, M.; Wang, S.; Li, Y.; Liu, X.; Tian, L. Synthesis, structural characterization and cytotoxic activity of triorganotin 5-(salicylideneamino)salicylates. Appl. Organomet. Chem. 2019, 33, e4715. [CrossRef]

43. Orioli, M.; Marinello, C.; Cozzi, R.; Piodi, L.P.; Carini, M. LC-MS/MS and FT-IR analyses of stones from a patient with Crohn's disease: A case report. J. Pharm. Biomed. Anal. 2004, 35, 1263-1272. [CrossRef] [PubMed]

44. McKinnon, J.J.; Fabbiani, F.P.A.; Spackman, M.A. Comparison of Polymorphic Molecular Crystal Structures through Hirshfeld Surface Analysis. Cryst. Growth Des. 2007, 7, 755-769. [CrossRef]

45. Pettinari, C.; Pettinari, R.; Xhaferai, N.; Giambastiani, G.; Rossin, A.; Bonfili, L.; Maria Eleuteri, A.; Cuccioloni, M. Binuclear 3,3',5,5'-tetramethyl-1H,H-4,4'-bipyrazole Ruthenium(II) complexes: Synthesis, characterization and biological studies. Inorg. Chim. Acta 2020, 513, 119902. [CrossRef] 